\title{
SURGICAL AND NON-SURGICAL THERAPY OF OBSTRUCTIVE SLEEP APNEA SYNDROME IN CHILDREN
}

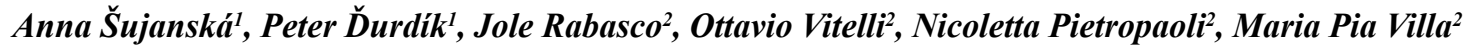 \\ Department of Paediatrics, Jessenius Faculty of Medicine in Martin, Commenius University in Bratislava, Martin, Slovak \\ Republic ${ }^{1}$; Neuroscience, Mental Health and Sense Organs Department, Pediatric Sleep Disease Centre, S. Andrea Hospital, \\ "Sapienza" University of Rome, Rome, Italy²
}

\begin{abstract}
Summary: Interventions of paediatric obstructive sleep apnea syndrome are complex, varied and multidisciplinary. The goal of the treatment is to restore optimal breathing during the night and to relieve associated symptoms. Evidence suggests that the surgical intervention with removal of the tonsils and adenoids will lead to significant improvements in the most incomplicated cases, as recently reported from a meta-analysis. However, post-operative persistence of this syndrome in paediatric population is more frequent than expected, which supports the idea of the complexity of this syndrome. Adenotomy alone may not be sufficient in children with OSAS, because it does not address oropharyngeal obstruction secondary to tonsillar hyperplasia. Continuous positive airway pressure can effectively treat this syndrome in selected groups of children, improving both nocturnal and daytime symptoms, but poor adherence is a limiting factor. For this reason, CPAP is not recommended as first-line therapy for OSAS when adenotonsillectomy is an option. It is now being investigated the incorporation of nonsurgical approaches for milder forms and for residual OSAS after surgical intervention. Althought adenotonsillar hypertrophy is the most common for OSAS in children; obesity is emerging as an equally important etiological factor. Therefore an intensive weight reduction program and adequate sleep hygiene are also important lifestyle changes that may be very effective in mitigating the symptoms of this syndrome. Pharmacological therapy (leukotriene antagonists, topical nasal steroids) is usually use for mild forms of OSAS and in children with associated allergic diseases. Special orthodontic treatment and oropharyngeal exercises are a relatively new and promising alternative therapeutic modality used in selected groups of children with OSAS.
\end{abstract}

Key words: Obstructive sleep apnea syndrome; Children; Therapy

\section{Introduction}

During the past decade paediatric obstructive sleep apnea syndrome (OSAS) has become widely recognized as a frequent and relatively common disorder with potentially serious clinical implications in childhood and has emerged as a major public health problem (1). OSAS is a sleep disordered breathing (SDB) characterized by a combination of repeated episodes of prolonged partial upper airway obstruction (obstructive hypopnea) and/or intermittent complete obstruction (obstructive apnea) that interrupts normal ventilation and normal sleep patterns (2). Prevalence of OSAS has been traditionally estimated to be $1 \%$ to $5 \%$ in the paediatric population $(2,3)$. Difficulty breathing and apnoeic pauses during sleep, snoring, restless sleep, frequent awakening during sleep and neurobehavioural disturbances (from subtle impairments of learning, attention and behaviour to prominent neurobehavioral deficits that may mimic attention-deficit/ hyperactivity disorder - ADHD and learning disabilities) are the typical symptoms usually present in children with OSAS. Diagnosis of this condition is usually based on physical examination, history and clinical evaluation confirmed by the polysomnography (PSG) (2). Standard overnight PSG is considering as a gold-standard test for establishing the presence and severity of OSAS in children (4). The presentation in children is much more varied and often difficult to diagnose based on individual symptoms compared with adults. Recently it has been reported that delayed diagnosis of this syndrome can lead to serious cardiorespiratory morbidity, metabolic complications, neurobehavioural consequences as well as an increase in insulin resistance, high blood pressure and the development of this syndrome in adulthood. This condition should be diagnosed, managed and treated aggressively with having these new repercussions $(1,2,4,5,6)$.

\section{Treatment}

Interventions for paediatric OSAS are varied, complex and often multidisciplinary. The goal of the treatment is to restore optimal breathing during the night and to relieve associated symptoms improved daytime functioning and minimizing negative impact. An early therapy based on the result of PSG plays an important role in a management of 


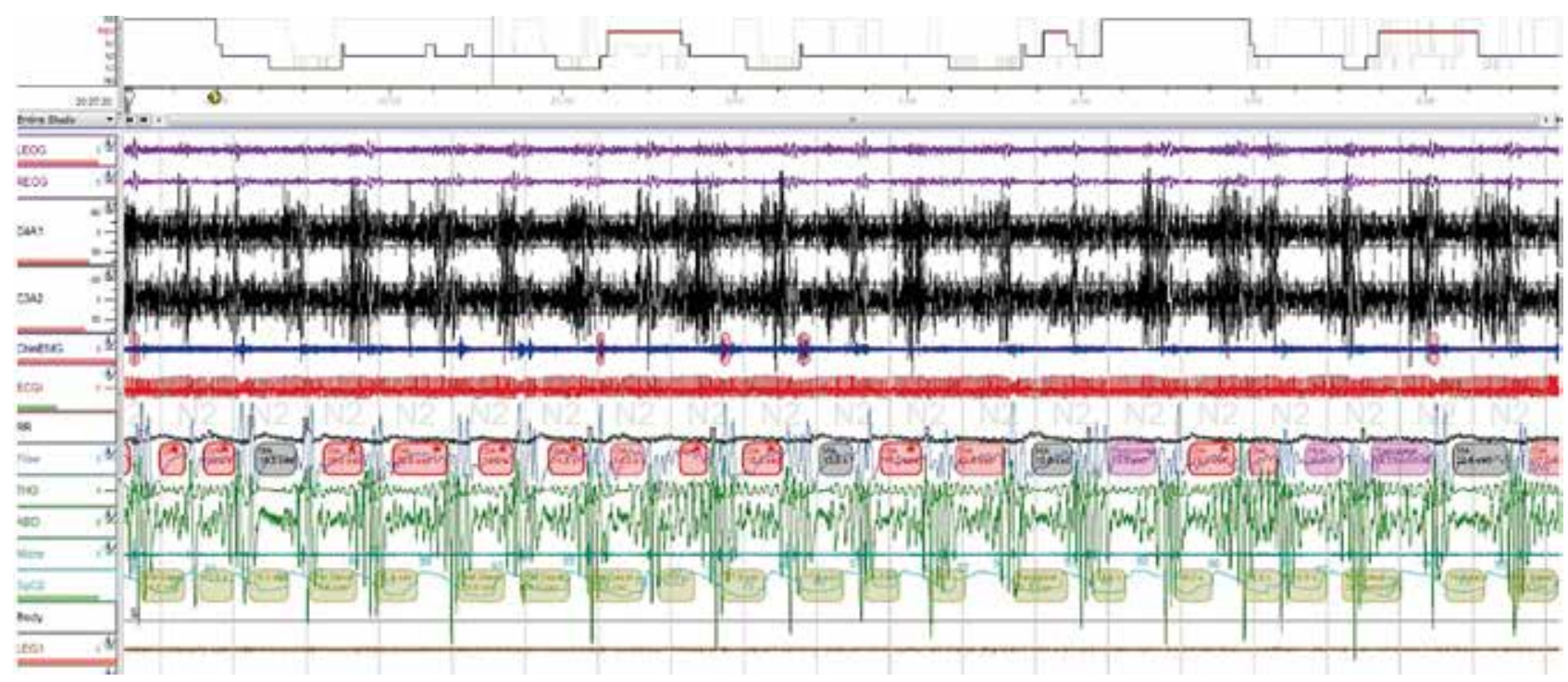

Fig. 1: Standard overnight polysomnography - severe obstructive sleep apnoe syndrome in our 11 years old boy (Apnoe Hypopnoe Index - AHI 80 events/hour).

children with OSAS. Early identification of this syndrome in paediatric population is desirable, because it is high-prevalence condition and identification and treatment can result in alleviation of current symptoms, prevention of sequelae, improved quality of life and decreased health care utilization $(1,2)$. The therapy needs to be evaluated carefully as the OSAS in children is likely to be multifactorial $(3,7)$.
Adenotonsillectomy is the most important first-line therapy for practical use in children with OSAS. In this review we present the recent view on the multitherapeutic stepwise approach to the phenotypes of pediatric OSAS. Notwithstanding, adenotonsillectomy is the primary therapy for OSAS in children, the efficacy and the resolution of OSAS after this surgical therapy remains uncertain, depending on

Tab. 1: Multi-therapeutic stepwise approach to the phenotypes of pediatric OSAS.

Adapted from Villa MP. Treatment of Paediatric Obstructive Sleep Apnoea with Oral Appliances. Buyers' Guide To Respiratory Care Products. ERS, 2014.

\begin{tabular}{|c|c|}
\hline \multirow{5}{*}{$\begin{array}{l}\text { Congenital phenotype } \\
\text { (retrogratia and micro- } \\
\text { gnatia, Pierre Robin } \\
\text { sequence) }\end{array}$} & 1. Maxillo-facial surgery mostly consisting in early mandibular advancement \\
\hline & 2. Orthodontic treatment (depending on the severity of OSA: after surgery or replacing surgery) \\
\hline & 3. Nasal CPAP (before surgery, or after surgery depending on residual disease) \\
\hline & 4. Medical therapy (topic and systematic anti-inflammatory drugs) \\
\hline & 5. Oropharyngeal exercise therapy if there is persistence of oral breathing after steps $1-3$ \\
\hline \multirow{5}{*}{$\begin{array}{l}\text { Common phenotype } \\
\text { (long face, narrow palate, } \\
\text { minor malocclusions, } \\
\text { adenotonsillar hyper- } \\
\text { trophy) }\end{array}$} & 1. Adenotonsillectomy \\
\hline & $\begin{array}{l}\text { 2. Orthodontic treatment by oral appliances (depending on the severity of OSA: after surgery } \\
\text { or replacing therapy) }\end{array}$ \\
\hline & 3. Nasal CPAP (after surgery depending on the presence of residual disease) \\
\hline & 4. Medical therapy (topic and systematic anti-inflammatory drugs) \\
\hline & 5. Oropharyngeal exercise therapy if there is persistence of oral breathing after steps 1 and 2 and 3 \\
\hline \multirow{5}{*}{$\begin{array}{l}\text { Adult type (obesita, } \\
\text { midface hypoplasia } \\
\text { and short neck) }\end{array}$} & 1. Hypocaloric diet \\
\hline & 2. Nasal CPAP or BiPAP depending on the compliance of child \\
\hline & 3. Orthodontic treatments by oral appliance of malocclusions and or narrow palate \\
\hline & 4. Medical therapy (topic and systematic anti-inflammatory drugs) \\
\hline & 5. Oropharyngeal exercise therapy if there is persistence of oral breathing after steps $1-3$ \\
\hline
\end{tabular}

Abbreviation: BiPAP - Bilevel Positive Airway Pressure, CPAP - Continuous Positive Airway Pressure, OSA - Obstructive Sleep Apnoe. 
the severity and on the association with other co-morbidities. Since residual disease is reported in a large proportion of children after this therapy, and children with OSAS display a complex phenotype (mild or major craniofacial anomalies or comorbid obesity), a multi-therapeutic approach to paediatric OSAS is required. A proposal model of therapy for paediatric OSAS is described in Table 1, depending on the prevalent phenotype expressed by the child: congenital type is represented by the phenotype starting from infancy and mostly related to the Pierre Robin sequence, with retrognatia and micrognathia; common type is represented by long, narrow palate and hypotonic lips and nose cartilage; and the adult type is characterised by obesity, a short neck and midface hypoplasia. Each phenotype may be associated with several degree of enlargement of adenoid and tonsils, which mostly occurs in the common type.

\section{Surgical therapy}

Adenotonsillar hypertrophy is the most common cause of OSAS in children. Therefore is surgical intervention with removal of the tonsils and/or adenoids an effective treatment, which provides more airway space (2). Outcome-based data reports the effectives of adenotonsillectomy as the first line surgical procedure for uncomplicated OSAS in children with hypertrophy of lymphoid tissues. This surgical therapy leads to significant improvement in polysomnographic parameters, in behavior and attention and likely improvement in cognitive abilities. Despite improvements in the majority of patients after adenotonsillectomy, a significant proportion of patients are left with persistent OSAS. In a relatively lowrisk population the estimate of residual OSAS ranges from a low of $13 \%$ to $29 \%$ when using an Apnea/Hypopnea Index $(\mathrm{AHI}) \geq 5$ events/hour as the criterion to a high of $73 \%$ when including obese children and adolescents and a conservative $\mathrm{AHI} \geq 1$ events/hour. Absence of snoring postoperatively is reassuring but may not be $100 \%$ specific, it may therefore be advisable to obtain a postoperative PSG in risk paediatric population even in the absence of reported persistent snoring. The present of residual OSAS after treatment is still now open and often discussed question. At the present there is no clear answer on the question, which kind of therapeutic modality chooses in children with residual OSAS $(2,8)$.

Althought, adenotonsillectomy in most children with OSAS is associated with a low complication rate, there are some risk groups of pediatric patients with this syndrome, who have an increased risk of postoperative complications. Risk factors include severe OSAS (AHI > 10 events/hour), age less than 3 years, obesity, recurrent infections of upper airways, presence of cardiac complications, neuromuscular diseases and craniofacial abnormalities (9). An important advantage of the objective documentation of the severity of OSAS by using nocturnal PSG should be the ability to predict the need for more intensive care after adenotonsillectomy on the basis of a higher risk of postoperative complications (postoperative respiratory complications and haemorrhage) (10). High risk patients should be monitored as inpatients postoperatively $(10,11,12)$.

Tonsillotomy, in which a portion of tonsil tissue is left to cover the musculature of the tonsillar fossa, is one of the possible techniques to decrease the morbidity associated with traditional tonsillectomy methods. There are only few studies comparing tonsillotomy with total tonsillectomy in children with OSAS (13). Some studies found that patients who undergo tonsillotomy have quicker recovery and less pain during the first few days compared with the children undergoing total tonsillectomy. However, tonsillotomy may be associated with possibility of greater intraoperative blood loss, tonsillar regrowth and with a higher risk of recurrent infections (14). Children undergoing tonsillotomy should be monitored carefully long-term to ensure that symptoms of OSAS related to tonsillar regrowth do not occur (2).

Adenotomy alone may not be sufficient in children with this syndrome, because it does not address oropharyngeal obstruction secondary to tonsillar hyperplasia (2).

\section{Non-surgical therapy}

\section{Positive airway pressure}

Positive airway pressure (PAP) is the mainstay of therapy for most adults, as well as in a selected groups of pediatric patients with OSAS. The term CPAP (continuous positive airway pressure) means the application of ventilatory support in the form of continuous positive pressure generated by the device. Treatment with CPAP is a safe, effective and tolerated therapeutic modality also in children (15). Continuous distending airway pressure is applied during the sleep using a nasal, nasal-oral or face mask and small compressor. CPAP acts as a pneumatic splint to maintain airway patency. By simultaneously increasing the functional residual capacity, this pressure also helps prevent oxygen desaturation even if airway obstruction breaks through. CPAP or bilevel positive airway pressure (BiPAP) are used for children who are not good surgical candidates, have sleep disordered breathing (SDB) associated with major craniofacial deformities, have residual OSAS after upper airway surgery or who have failed previous surgical treatment. Studies demonstrated significant improvement in sleepiness, snoring, PSG parameters and oxyhemoglobin saturation while using PAP $(2,16)$.

Alternative procedure for CPAP is the use of BiPAP. In this method is inspiratory pressure identical to effective CPAP pressure and expiratory pressure is lower. A randomised control trial of CPAP versus BiPAP in children with OSAS who were unsuitable for AT found no difference between these methods. There were also no significant differences in adherence between the CPAP and BiPAP groups in children. CPAP pressures change over the time in children, presumably because of growth and development. Therefore, it is recommended that CPAP pressures be often and periodically reassessed in children (16). 
In summary, CPAP is recommended as treatment if AT is not performed or if OSAS persists postoperatively in paediatric population. Several studies have confirmed that nasal CPAP is an effective in the treatment of both symptoms and polysomnographic evidence of OSAS, even in young children and also in selected groups of pediatric patients with OSAS. However, adherence can be a main barrier to effective CPAP use and for this reason, CPAP is not recommended as first-line therapy for OSAS when AT is an option $(17,18)$. This therapy is often not good tolerated by young children, children with Down and Prader-Willi syndrome and also by their parents. It is important training of the family and child, use behavioural modification techniques, daytime training as well as finding the appropriate nasal interface $(15,16,17)$.

\section{Medical therapy}

Increased activation of inflamamatory processes and oxidative stress have been proposed to explain the morbid consequences of sleep disordered breathing, which may be further modulated by lifestyle, genetic and environmental factors. Therefore, it is now being investigated the incorporation of nonsurgical approaches for children with OSAS that target those inflammatory processes. Pharmacological therapy is usually use for mild forms of this syndrome (AHI $<5$ events/hour), in children with associated allergic diseases and for residual obstructive sleep apnoe syndrome (19). There is still debate about the possibility of using topic nasal steroids and leukotriene antagonists. An older study did not demonstrate a therapeutic effect of systemic corticosteroid use in this condition (20). It was published only few works that retrospectively evaluated the use of local nasal corticosteroids, leukotriene antagonists or combination of both in children with OSAS. This treatment can improve symptoms (reduce mucosal edema and volume of adenoids and tonsils) of mild forms of OSAS and children with allergy, but the clinical effect is small. On the basis of these studies, intranasal steroids may be considered for treatment of mild OSAS (AHI $<5$ events/hour), but should not be used as the primary treatment of moderate or severe OSAS. The longterm effects of intranasal steroids are not known, follow-up evaluation is needed to monitor for adverse effects and to ensure that the OSAS does not recur. There is an absent of studies that specifically evaluated children who had atopy or chronic rhinitis, although one study mentioned that similar improvements were seen in children who had a history of allergic symptoms compared with those without $(21,22)$. There is a need for further study to determine whether children who have atopy are more likely to respond to this therapy is needed. Data are insufficient at this time to recommend treatment in children of OSAS with leukotriene antagonists (2). Good nose hygiene and the lavage of the nasal cavity with hypertonic solution are recommended as support local therapy especially in mild forms of OSAS. Systematic and local inflammation can also contribute to the increased resistance at the adenotonsillar level in children. Local and systemic activations of leukotrienes and corticosteroid receptors play a significant role in pathophysiology of this syndrome in chidren, there are not enough data to conclude whether the inflammatory mechanisms are a component of the cause of OSAS or rather a consequence of the recurrent upper airway collapse and mechanical trauma $(19,23,24)$.

\section{Myofunctional therapy}

Upper airway muscle function plays an important role in maintenance of upper airway patency and contributes to the genetic of OSAS in children (19). Oropharyngeal exercises are a set of repetitive isotonic and isometric exercises tongue, soft palate and lateral pharyngeal walls, leading to increased throughput upper respiratory tract and thus to obtain good breathing habits, speech, swallowing and chewing. These exercises are derived from speech-language pathology and include soft palate, tongue and stomatognathic function exercises facial as well as muscle exercises (25). Upper airway exercises treatment could be considered as a new therapy for OSAS and snoring because of its direct action on oral motility. The myofunctional therapy includes the correct of functions by means of functional exercises (respiratory, suction, swallowing and chewing), use of the stomatognatic structures and muscular exercises with the aim of increasing the tonus and mobility of oral and cervical structures $(25,26)$.

Nowadays, only few studies have recognized the effectiveness of oropharyngeal exercises in children with OSAS reduction in mouth breathing, nasal obstruction and snoring (25). But there is still an open question of possibility of using these exercises as a simple method for treatment with mild to moderate obstructive sleep apnea syndrome and also for the residual OSAS in paediatric population. In adult patients with moderate OSAS, oropharyngeal exercises improved subjective measurements of snoring, daytime sleepiness, sleep quality and objective measurements of this syndrome. These studies confirmed that upper airway exercises can achieve subjective and objective improvement of symptoms and PSG abnormalities in patients with mild to moderate OSAS and so can be considered as complementary therapy to adenotonsillectomy to effectively treat pediatric OSAS $(25,26,27)$.

\section{Orthodontic therapy}

Nowadays, orthodontists play an important in the management of obstructive sleep apnoe syndrome. The theme of craniofacial and orthodontic abnormalities associated with SDB in children are still not enough discussed. A narrow upper airway with maxillary constriction and some degree of mandibular retrusion is a common phenotype of OSAS in paediatric population and children in such cases are typically described as having a narrow, long face (27). Orthodontic treatment is a relatively new therapeutic modality in selected groups of children with this syndrome and 


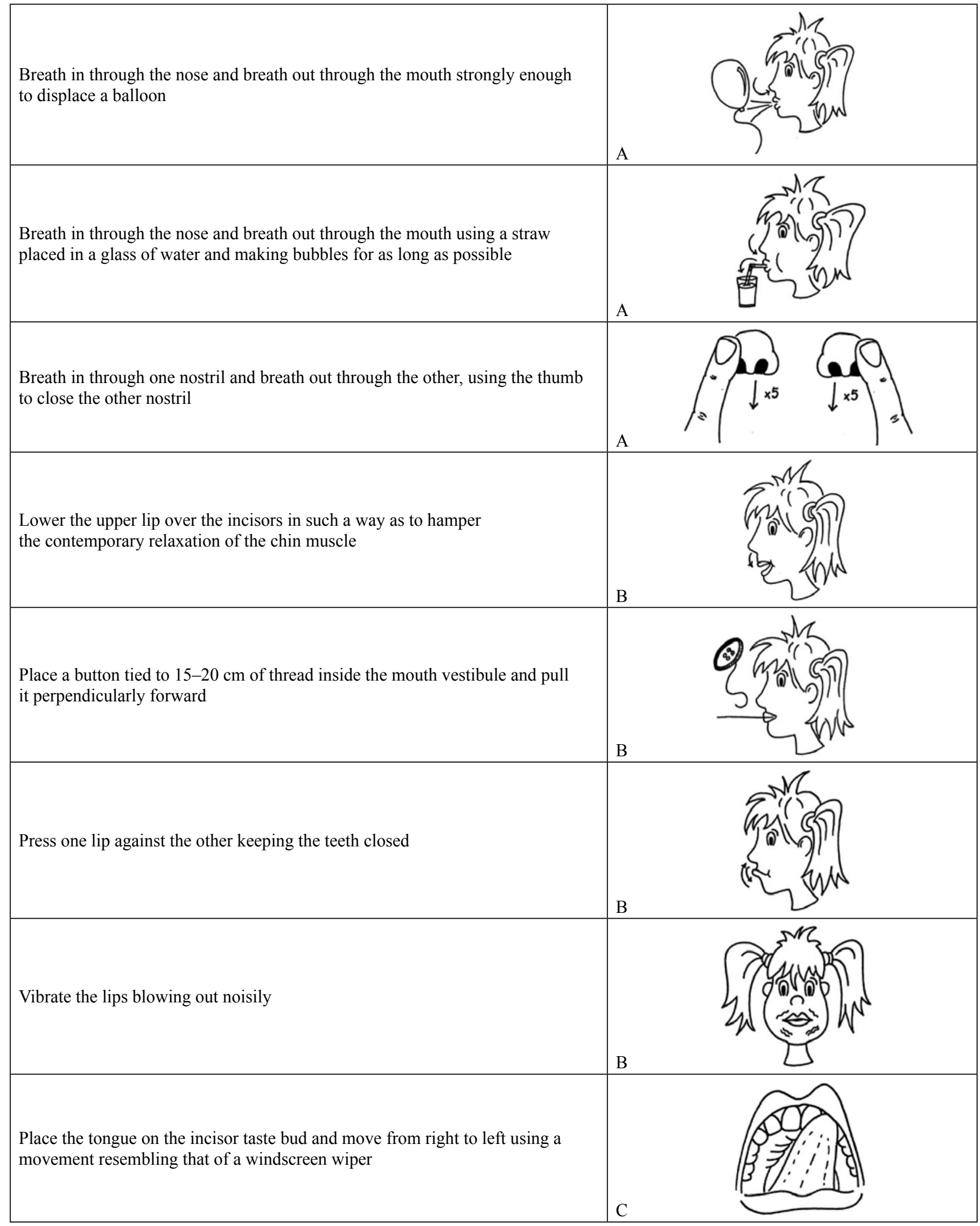

Fig. 2: Examples of some oropharyngeal exercises, $\mathrm{A}$ - nasal breathing rehabilitation, $\mathrm{B}$ - labial seal and lip tone exercises, $\mathrm{C}$ - tongue posture exercises. Adapted from Villa MP, et al. Sleep Breath, 2014. 
malocclusion (28). This therapy by means of oral devices is considered to represent a potential or supplementary treatment. Oral appliances may improve upper airway patency during sleep by enlarging the upper airway and by decreasing collapsibility of upper airway, thereby improving upper airway muscle tone. Rapid maxillary expansion (RME), mandibular retropositioning and modified monoblock (MM) are the available treatment options in paediatric population (27). RME is a dentofacial orthodontic procedure used in young patients (start after the age of 4 - when deciduous dentition is complete) with constricted maxilary arches. There are three RME methods: orthodontic, orthosurgical and surgical expansion. Indication depend on the degree of deformity. Orthodontic expanion, also know as a RME, is performed using a a fixed oral appliance with expansion screw anchored on selected teeth. The expansion screw is periodically activated so as to open the midpalatal suture, which results in the maxillary bones diverging from each other. RME is usually removed after 12 months and patient undergo monthly follow-up assessments until the therapy ends $(28,29)$. RME improves nasal breathing by increasing the transverse dimensions of the maxilly.

There were designed only few studies with this type of therapy in selected group of pediatric populations. Findings in 12 month open clinical trial published by authors in 2007 suggested that young children with OSA may benefit from early orthodontic therapy with an RME (28). After 36 months follow up the authors published in 2011 the effects of such a treatment were found to persist 24 months after the end of treatment (29). Despite improvements in AHI after RME (AHI before therapy $6.3 \pm 4.7$ vs AHI 12 and 24 months after therapy $2.4 \pm 2$ and $2.3 \pm 1.7$ ), a residual OSAS was present in $68 \%$ of patients after orthodontic treatment. An integrated therapy is necessary and it should be done as soon as possible. In summary, rapid maxillary expansion is an orthodontic technique that holds promise as an alternative treatment of OSAS in children with maloclusion (28, 29, 30).

\section{Lifestyle changes}

There are some lifestyle changes, that may be very effective in mitigating the symptoms of paediatric OSAS.

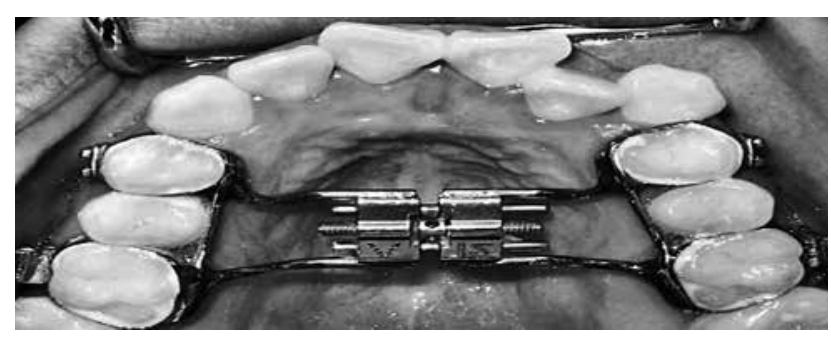

Fig. 3: Rapid maxillary expansion (RME). Adapted from Kilic N, et al. Int J Pediatr Otorhinolaryngol 2008.
Nowadays, the prevalence of childhood obesity is increasing $(31,32)$. An intensive weight reduction program is an important first line step for obese or overweight paediatric patients. Weight loss has been recommended on the basis that it should decompress the upper airway and promote its patency, particularly if weight gain has coincided with worsening of the symptoms (33). OSAS may aggravate gastroesophageal reflux or vice versa. Children with significant sleep apnea should avoid eating large amounts just before bedtime, especially the case if children are being treated with CPAP, which can lead to air swallowing and gastric distention. However, there is a paucity of data regarding the effects of weight loss on OSAS in children and adolescents. Finally, along with many other health-related benefits, achieving weight loss and increasing exercise and dietary management seems to be beneficial for OSAS and should be recommended along with other interventions for OSAS in obese paediatric population $(2,34,35,36)$. Other life style modifications are designed to improve sleep hygiene, which is very important for any individuals. These include measures to improve the sleep environment (child's bedroom should be cool, quiet and comfortable), improving the sleepwake patterns, increasing physical activity during the day, preparation for sleep by mentally winding down in the evenings and avoiding daytime naps and avoiding caffeinated drinks in the evening and other stimulants dinks. Avoidance of using alcohol and drugs that suppress respiratory reflexes is also important in adolescents because of supporting the relax of pharyngeal muscles allowing the pharyngeal walls to collapse more easily. Also smoking results in irritation and swelling of the pharyngeal space, increasing the likelihood of snoring and OSAS. There have been only few clinical studies in adult population of sleep hygiene, but sleep deprivation has been shown to increase the collapsibility of the upper airway. But it remains uncertain how effective they are in reducing symptoms and if they are effective especially in children population with OSAS $(5,33)$.

\section{Position therapy}

Althought, several retrospective studies evaluated the effect of body position during sleep on OSAS in paediatric population, these studies had conflicting results. One study found that young children had an increased AHI in the supine position, another study did not found a positional change in AHI $(36,37)$. No study evaluated the effect of changing body positions or the feasibility of maintaining a child in a certain position overnight. Therefore, at the present, there are no recommendations that can be made with regard to positional therapy for OSAS in children $(2,38)$.

\section{Conclusion}

Early identification of paediatric OSAS is desirable, because it is a highprevalence disorder and accurate diagnosis and treatment can result in alleviation of current symptoms, 
improved quality of life, prevention of sequelaes, education of parents and decreased health care utilization. Interventions for paediatric OSAS are multidisciplinary. Adenotonsillectomy emerges as the leading therapy approach for children with hypertrophy of lymphoid tissues and OSAS. CPAP is recommended as treatment if adenotonsillectomy is not performed or if OSAS persist postoperatively. Pharmacological therapy is usually use for mild forms of OSAS and in children with associated allergic diseases. Special orthodontic treatment and oropharyngeal exercises are a relatively new therapeutic modality used in selected groups of children with OSAS.

\section{Acknowledgements}

This work was supported by the project "Center of experimental and clinical respirology I, II”, co-financed from EU sources.

\section{References}

1. Tauman R, Gozal D. Obstructive Sleep Apnea Syndrome in Children. Expert Review of Respiratory Medicine 2011; 3: 425-40.

2. Marcus SL. Diagnosis and Management of Childhood Obstructive Sleep Apnea Syndrome. Clinical Practise Guideline. Pediatrics 2012; 130: 576-84.

3. Powell S, Kubba H, Brien CH, et al. Clinical Review: Paediatric obstructive sleep apnoea. BMJ 2010; 340(14): 1018-23.

4. Aurora RN, Zak RS, Karippot A, Lamm CI. Practice Parameters for the Respiratory Indications for Polysomnography in Children. Sleep 2012; 34: 379-85.

5. Mindell JA, Owens JA. A Clinical Guide to Pediatric Sleep: Diagnosis and Management of Sleep Problems. Philadelphia, 2010

6. Sujanska A, Durdik P, Banovcin P. The Recent View on the Obstructive Sleep Apnoea Syndrome in Children. Acta Medica Martiniana 2012; 12: 11-18.

7. Chan J, Edman JC, Koltai PJ. Obstructive Sleep Apnea in Children. Am Fam Physician 2004; 69: 1147-54.

8. Bhattacharjee R, Kheirandish-Gozal L, Spruyt K. Adenotonsillectomy outcomes in treatment of obstructive sleep apnea in children: a multicenter retrospective study. Am J Respir Crit Care Med 2010; 182: 676-83.

9. Hill CA, Litvak A, Canapari C. A pilot study to identify pre- and peri-operative risk factors for airway complications following adenotonsillectomy for treatment of severe pediatric OSA. Int J Pediatr Otorhinolaryngol 2011; 75: 1385-90.

10. Sanders JC, King MA, Mitchell RB. Perioperative complications of adenotonsillectomy in children with obstructive sleep apnea syndrome. Anesth Anal 2006; 103: 1115-21.

11. Ye J, Liu H, Zhang G. Postoperative respiratory complications of adenotonsillectomy for obstructive sleep apnea syndrome in older children: prevalence, risk factors, and impact on clinical outcome. J Otolaryngol Head Neck Surg 2009; 38: 49-58.

12. Nosal S, Sutovska M, Nosalova G, et al. Age-dependent changes of airway obstruction parameters. Journal of Physiology and Pharmacology 2007; 58: 493-500.

13. Eviatar E, Kessler A, Shlamkovitch N. Tonsillectomy vs. partial tonsillectomy for OSAS in children - 10 years post-surgery follow-up. Int J Pediatr Otorhinolaryngo 2009; 73: 637-40.

14. Celenk F, Bayazit YA, Yilmaz M. Tonsillar regrowth following partial tonsillectomy with radiofrequency. Int J Pediatr Otorhinolaryngol 2008; 72: 19-22.

15. Downey R, Perkin RM, Mac Quarrie J. Nasal continuous positive airway pressure use in children with obstructive sleep apnea younger than 2 years of age. Chest 2000; 117: 1608-12.

16. Marcus CL, Rosen G, Ward SLD. Adherence to and effectiveness of positive airway pressure therapy in children with obstructive sleep apnea. Pediatrics 2006; 117: $442-51$.
17. Koontz KL, Slifer KJ, Cataldo MD. Improving pediatric compliance with positive airway pressure therapy: the impact of behavioral intervention. Sleep 2003; 26 : $1010-15$.

18. Uong EC, Epperson M, Bathon SA. Adherence to nasal positive airway pressure therapy among school-aged children and adolescents with obstructive sleep apnea syndrome. Pediatrics 2007; 120: 1203-11.

19. Kheirandish-Gozal L, Gozal D. Sleep Disordered Breathing in Children. A Comprehensive Clinical Guide to Evaluation and Treatment. Humana Press, 2012.

20. Al-Ghamdi SA, et al. Do systemic corticosteroids effectively treat obstructive sleep apnea secondary to adenotonsillar hypertrophy? Laryngoscope 1997; 107(10): $1382-87$.

21. Kheirandish-Gozal L, Gozal D. Intranasal budesonide treatment for children with mild obstructive sleep apnea syndrome. Pediatrics 2008; 122(1): 149-55.

22. Alexopoulos EI, Kaditis AG, Kalampouka E. Nasal corticosteroids for children. Pediatr Pulmonol 2004; 38: 161-67.

23. Goldbart AD, Goldman JL, Veling MC. Leukotriene modifier therapy for mild sleep-disordered breathing in children. Am J Respir Crit Care Med 2005; 172: 364-70.

24. Goldbart AD, Veling MC, Goldman JL. Glucocorticoid receptor subunit expression in adenotonsillar tissue of children with obstructive sleep apnea. Pediatr Res 2005; 57: $232-36$.

25. Guimaraes KC, Drager LF, Genta PR. Effects of Oropharyngeal Exercises on Patients with Moderate Obstructive Sleep Apnea Syndrome. Am J Respir Crit Care Med 2009; 179: 962-66.

26. Guilleminault C, Huang YS, Monteyrol PJ. Critical role of myofascial reeducation in pediatric sleep-disordered breathing. Sleep Med 2013; 14: 518-25.

27. Kheirandish-Gozal L, Gozal D. Sleep Disordered Breathing in Children. A Comprehensive Clinical Guide to Evaluation and Treatment. Humana Press, 2012.

28. Villa MP, Malagola C, Pagani J. Rapid maxillary expansion in children with obstructive sleep apnea syndrome: 12-month follow-up. Sleep Med 2007; 8: 128-34.

29. Villa MP, Rizzoli A, Miano S. Efficacy of rapid maxillary expansion in children with obstructive sleep apnea syndrome: 36 months of follow-up. Sleep Breath 2011; 15: 179-84.

30. Pirelli P, Saponara M, Guilleminault C. Rapid maxillary expansion in children with obstructive sleep apnea syndrome. Sleep 2004; 27: 761-66.

31. Ogden CL, Carroll MD, Curtin LR. Prevalence of overweight and obesity in the United States. JAMA 2004; 295: 1549-55.

32. Krystofova J, Jesenák M, Bánovcin P. Bronchial asthma and obesity in childhood. Acta Medica (Hradec Kralove) 2011; 54: 102-6.

33. Shneerson J, Wright J. Lifestyle modification for obstructive sleep apnoea. Cochrane Database Syst Rev. 2009; 1, CD002875.

34. Verhulst SL, Franckx H, Van Gaal L. The effect of weight loss on sleep-disordered breathing in obese teenagers. Obesity 2009; 17: 1178-83.

35. Jesenak M, Havlicekova Z, Szepeova R, Banovcin P. Extrafageálne prejavy refluxnej choroby pažeráka u detí. Mimojícnové projevy refluxní choroby. Havlíčkủv Brod: Tobiáš, 2013: 223-35.

36. Varechova S, Mikler J ml, Murgas D, Dragula M, Banovcin P, Hanacek J. Cough reflex sensitivity in children with suspected and confirmed gastroesophageal reflux disease. Journal of Physiology and Pharmacology 2007; 58: 717-27.

37. Dayyat E, Maarafeya MM, Capdevila OS. Nocturnal body position in sleeping children with and without obstructive sleep apnea. Pediatr Pulmonol 2007; 42 : 374-79.

38. Zhang XW, Li Y, Zhou F. Association of body position with sleep architecture and respiratory disturbances in children with obstructive sleep apnea. Acta Otolaryngol 2007; 127: 1321-26.

39. Ravesloot MJL, Maanem JP, Vries N. The undervalued potential of positional therapy in position-dependent snoring and obstructive sleep apnea - a review of the literature. Sleep Breath 2012; 17: 39-49.

40. Villa MP, Brasili L, Ferretti A, Vitelli O, Rabasco J, Mazzotta AR, Pietropaolo N, Martella S. Oropharyngeal exercises to reduce symptoms of OSA after AT. Sleep Breath 2014; in press.

41. Kilic N, Oktay H. Effects of rapid maxillary expansion on nasal breathing and some naso-respiratory and breathing problems ingrowing children: a literature review. Int J Pediatr Otorhinolaryngol 2008; 72(11): 1595-601.

42. Villa MP. Multitherapeutic stepwise approach to the phenotypes of pediatric OSAS. Treatment of Paediatric Obstructive Sleep Apnoea with Oral Appliances. Buyers' Guide to Respiratory Care Products. ERS, 2014: 26-30.

Received: $11 / 09 / 2014$

Accepted in revised form: 12/02/2015

\section{Corresponding author:}

Peter Ďurdík, Department of Paediatrics, Jessenius Faculty of Medicine in Martin, Commenius University in Bratislava, Kollarova 2, 036 01, Martin, Slovak Republic; e-mail: peter.durdik@gmail.com 